\title{
Synchronous Study of Ferroresonance and Inrush Current Phenomena and their Related Reasons in Ground Power Networks
}

\author{
Amin Akrami, Dezfool Azad Islamic University, Mohammad Ali Ghaderi, Dezfool Azad Islamic University, \\ Saeed Rostami Ghadi, Dezfool Azad Islamic University
}

\begin{abstract}
Energizing the power transformers usually results in flowing very high inrush currents. This harmful current can be minimized using controlled switching and considering the value of residual flux. But nowadays, developing the ground power networks results in high increment of ferroresonance phenomenon occurrence due to the line' capacitance reactance and nonlinear inductive reactance of power transformer's core. In this study, these transient phenomena and their cause have studied synchronously.
\end{abstract}

Keywords: inrush current, ferroresonance, ground power networks, controlled switched

\section{INTRODUCTION}

Energizing the power transformers is one of the most common applications in power systems. Energizing the power transformers often results in flowing high inrush currents, which finally reduce magnetizing current a little. Many researches and studies have been conducted on reducing the inrush current, controlled switching method is one of the most common ones [1]. The controlled switching method is for reducing the magnetizing inrush current of transformers that make a significant reduction in inrush current, using serial switching of different phases and considering the residual flux existing in them. On the other hand, we can neglect the capacitance capacity in different parts any more, since recent global growing of the ground power networks. This generally results in ferroresonance phenomenon occurrence. This phenomenon is generally caused by the line's capacitance reactance with nonlinear inductive reactance of power transformer's core.

Here, we examine the conditions in which we can show that the controlled switching method presented in [1] not only results in reducing the inrush current in ground power networks, but also create intensive ferroresonance in these networks and put an additional voltage on the network and transformer. In the next sections of this study, at first the inrush current and ferroresonance phenomenon and their effects and consequents will be introduced, and then a ground power network will be studied after transformer energizing, using controlled switching.

\section{INRUSH CURRENT PHENOMENON}

The equivalent circuit of a single-phase transformer is shown in Fig.1 [2]. $R_{P}$ and $X_{P}$ are the resistance and inductance of primary winding, respectively. $\mathrm{R}_{\mathrm{S}}$ and $\mathrm{X}_{\mathrm{S}}$ are the resistance and inductance of secondary winding, respectively. Parallel reactance, $\mathrm{X}_{\mathrm{C}}$, denotes the magnetic index of transformer iron core, and $\mathrm{R}_{\mathrm{C}}$ denotes ferro-losses of the core (hysteresis and eddy current). $\mathrm{I}_{\mathrm{m}}$ current in the parallel reactance, is the required magnetizing current for creating the necessary flux in transformer core. This parallel reactance has a flux nonlinear index against current with a knee point that only is 0.05 to 0.15 pu higher than performance nominal flux. Transformers core (or parallel reactance) flow a very low magnetizing current for maintaining this nominal flux. Also the magnetizing current or lag flux of applied voltage toward the primary side is approximately 90 degrees in steady state conditions. When the transformer is de-energized, an amount of residual flux will be saved in the core.

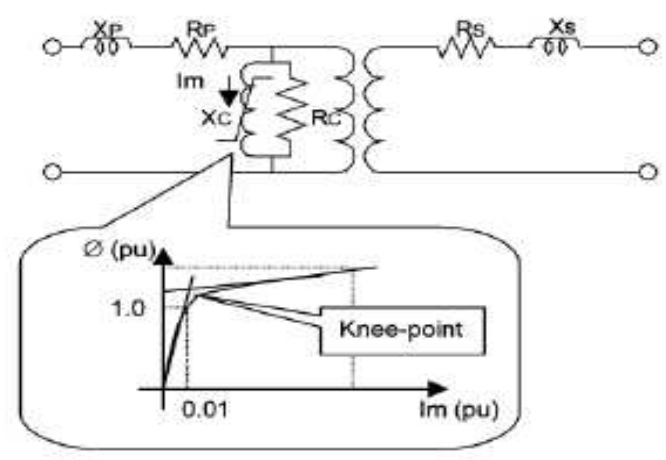

Fig.1. equivalent circuit of single-phase transformer

Assume that the transformer shown in Fig.1 is primarily energized by zero residual flux. When the transformer is switched, the instantaneous value of voltage will be equal to zero. For operating the transformer in steady state, it is required to consider the value of $90^{\circ}$ the magnetizing flux (or current) in peak and lag value. Since flux can't reach the peak value instantaneously, it starts increasing from zero and after one quadrant of cycle reaches 1 pu value, and when passing half of switching it reaches $2 \mathrm{pu}$. This phenomenon is usually called "flux double effect." If any residual flux is remained during switching and its polarity positioned in direction of flux inducing after switching, the maximum flux can reach $2 \mathrm{pu}$.

In this condition, considering the nonlinear index of current flux, transformer is entered the saturation region and becomes so hot, consequently its core will need a very high magnetizing current during switching. Basically, the ferro core 
will act as an aerial-core inductor with very low parallel reactance. Flux and current reach the steady state value slowly, depending on the proportion of resistance and inductance including source impedance, winding, and magnetized branch. Continuation and inrush current amplitude is a function of two basic factors [3, 4]. The first factor is about transformer and the other factor is about power system. Generally the following items can be considered:

1. Nominal power of transformer

2. Materials used for constructing transformer's core

3. Residual flux before transformer connection

4. Short circuit power in common coupling point

5. Distance between power post and transformer

Items 1 to 3 are features related to transformers, while items 4 and 5 are features related to power systems in which transformer are energized.

However, the resulted inrush current has very high amplitude and it is in short-circuit current range, and it may create some dynamic stress in transformer winding [5]. The amplitude of these currents usually dose not exceed the one resulted in transformers, but the continuation of these stresses and their occurrence number usually exceeds the short circuit current that the protective relays interrupt it in few msec. Moreover long continuation results in damaging in maintenance mechanical structure of windings. Also from the perspective of power quality, magnetizing inrush current can be considered as a distorted wave with two types of disturbances [3, 4]:

1. Nonbalances
2. Harmonics

\section{PREDICTING THE MAXIMUM INRUSH CURRENT AND RESULTING SAG VOLTAGE.}

Using equilibrium circuit of Fig. 1 is a simple method for detecting the maximum inrush current sag voltage. Inrush current cant exceeds $1 / \mathrm{X}+\mathrm{X}_{\mathrm{P}}+\mathrm{X}_{\mathrm{C}(\min )}$, where $\mathrm{X}$ is the source reactance of the bus in which the transformer is energized, $X_{P}$ is reactance in the transformer primary side, $X_{C(\min )}$ is the minimum magnetizing reactance that introduces the maximum flux created after transformer switching. Although $\mathrm{X}_{\mathrm{C}(\min )}$ can be obtained from no-load test and hysteresis index of transformer ferro core, but it isn't available on transformer board since the transformer ferro core acts as an aerial core in high saturation degree, it is recommended in [6] that the aerial core inductance is twice the short circuit inductance. That is, $\mathrm{X}_{\mathrm{C}(\min )}$ typically can be assumed as $2\left(\mathrm{X}_{\mathrm{P}}+\mathrm{X}_{\mathrm{S}}\right)$ or $2 \mathrm{X}_{\mathrm{t}}$, where $\mathrm{X}_{\mathrm{t}}$ is the sum of primary and secondary reactance. Considering the value of $\mathrm{X}_{\mathrm{C}(\mathrm{min})}$, the inrush current cant exceeds $1 / \mathrm{X}+\mathrm{X}_{\mathrm{P}}+2 \mathrm{X}_{\mathrm{t}}$. If the leakage reactance of windings wasn't available individually, usually it will be assumed as $X_{t} / 2$ in practical studies [7]. Therefore, the maximum sag voltage can be estimated using $\mathrm{X} / \mathrm{X}+2.5 \mathrm{X}_{\mathrm{t}}$.
IV. THREE-PHASE FERRORESONANCE PHENOMENON

\section{A. Ferroresonance principals}

There are several ways to understand ferroresonance phenomenon. RLC serial circuit review is one of the simplest one. A voltage source with an arbitrary frequency is shown in Fig. 2.

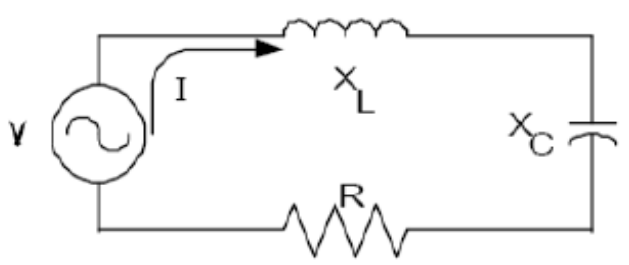

Fig.2. a RLC serial circuit for describing ferroresonance phenomenon

$\mathrm{X}_{\mathrm{L}}, \mathrm{X}_{\mathrm{C}}$ are assumed as inductive and capacitance reactance respectively. Also it is assumed that the $\mathrm{R}$ value is so lower than $X_{L}, X_{C}$. So the amplitude of circuit current is as the Equ.1.

$$
I=\frac{V}{R+X_{L}-X_{C}} \cong \frac{V}{X_{L}-X_{C}}
$$

It the $X_{C}$ changed and $K$ and $X_{L}$ assumed as constant, circuit current will be equal to $\mathrm{V} / \mathrm{X}_{\mathrm{L}}$ when $\mathrm{X}_{\mathrm{C}}=0$, and when $\mathrm{X}_{\mathrm{C}}$ has a high value, the circuit current will be significantly low. Between these two states, when $X_{C}=X_{L}$ the circuit current increased significantly but it is limited to $R$ (i.e. $I=V / R$ ).

High current can results in producing a significant additional voltage. Current amplitude is plotted against $\mathrm{X}_{\mathrm{C}}$ in Fig. 3 the possibility of $\mathrm{X}_{\mathrm{C}}=\mathrm{X}_{\mathrm{L}}$ is high, since this value was assumed as constant and linear in each moment. However, $\mathrm{X}_{\mathrm{L}}$ changed in ferro core transformer, consequently the possibility of $\mathrm{X}_{\mathrm{C}}=\mathrm{X}_{\mathrm{L}}$ will increased significantly.

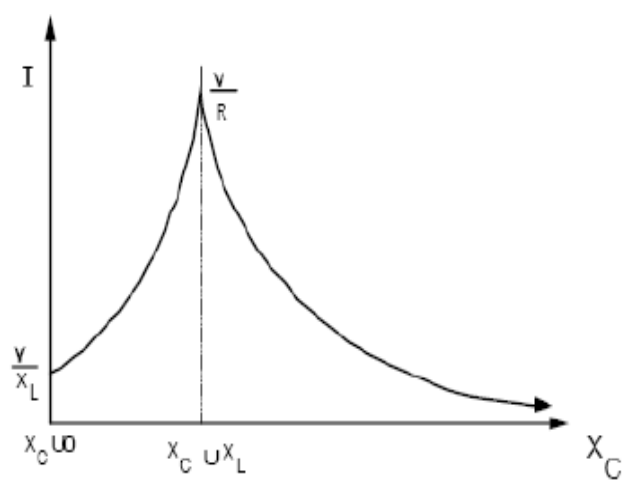

Fig.3. current in RLC serial circuit against $\mathrm{X}_{\mathrm{C}}$ value

\section{B. Effective factors}

Ferroresonance phenomenon generally appeared when a capacitance reactance becomes serial with a nonlinear inductive reactance. But practically there are some other factors that effect on this phenomenon such as design, 
protective, and applicative parameters. These factors have the following descriptions:

- Conditions that one or two fuse react(s) or we have delayed switching for opening and closing. (Similar to what we do for controlling the inrush current.)

- Connection Types of primary and secondary windings

- Design of transformer core and using low-loss transformers

- Transformer with low-level or no load conditions

- Capacitance capacity resulted from ground cables, aerial transmission lines, parallel capacitors, scattered capacitance capacity of transformers, and capacitance degree of circuit breakers

- Network specifications (nominal voltage, short circuit power, transformer power)

- Initial conditions including residual flux, switching time, circuit losses and capacitance loads.

Although until three last decays ferroresonance problems were limited to specific conditions, but high development of electrical networks resulted in ferroresonance phenomenon analyze to become more complicated. Therefore, the factors which make this phenomenon complicated are as follows:

- Increasing usage of ground cables with high capacitance capacity

- Single phase connection and separation (for example, controlled switching)

- Developing usage of lightning rod, MOV type

- Using optimized transformer cores with core low looses having different frequency responses.

\section{Ferroresonance conditions}

During past years, three-phase distribution transformers usually had delta, nonearthed star, and open delta primary windings. A ferroresonance circuit that is created by energized single-phase and parallel capacitors is shown in Fig.4.

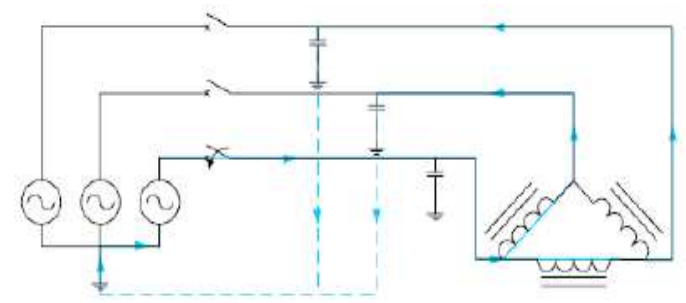

Fig.4. single phase performance of three phase nonearthed transformer

Distribution system increasing make ferroresonance phenomenon more complicated. Therefore, earthed star transformer is mostly used in primary side in most countries. (For example in USA, 79 percent of distribution systems utilize earthed star arrangement [8].)

If we use earthed primary winding, then we have to use a special type of core considering the connection type. Also the using procedure of earthed transformers should be conducted using transformers without any magnetic coupling and capacitance capacity between phases. (Such as three phase transformers are made of three single phase transformers.) In this method, each phase dose not induce any voltage in other ones, it is likely to produce ferroresonance between capacitance banks and inductive reactance. These conditions are shown in Fig.5.

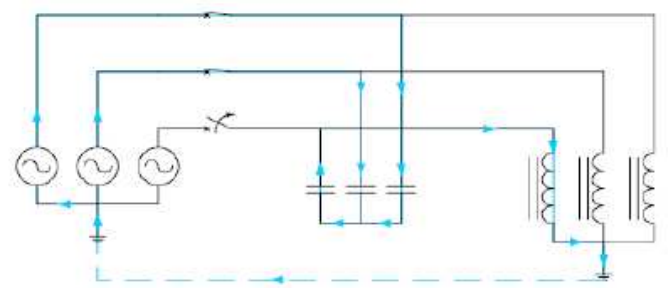

Fig.5. ferroresonance phenomenon's effects and consequents

As mentioned earlier in this study, there are so many factors contributing in ferroresonance phenomenon that although they haven't any harmonic contribution but they have an important role in creating that phenomenon. Ferroresonance phenomenon can have the following results:

Creating hearing noise, additional heating, rod lightning destroying, effecting on power quality, and producing voltage flicker [9].

\section{V.CONTROLLED SWITCHING PROCEDURE}

As we mentioned in previous sections, the performance of circuit breakers poles should be controlled separately in order to achieve minimum rate of inrush current in switching conditions. Such a procedure is called "controlled switching." In following of this section, the case will be studied completely.

\section{A. Controlled switching (if the residual flux equals to zero)}

Transformer banks including single phase but without delta winding can be considered as three single transformers. However, the most basic power transformers are produced by at least one delta winding that. Therefore, energizing the first phase changes the static residual in two other phases. If the residual flux equals to zero in all phases, then energizing in voltage peak is the best time for closing the first phase in $\mathrm{HV}$ side. After closing the first phase, a dynamic flux will appear in the other two phases. For achieving free switching in these phases, second and third phases should be energized after $5 \mathrm{~ms}$ synchronously when the waiting and dynamic fluxes of core are equal in all three phases [10].

\section{B. Controlled switching with high flux density}

Total residual flux always equals zero, for three-leg coretype transformers or if transformers have at least one delta winding. This case is not available for shell-type transformers with five-leg core and windings without delta winding.

If residual flux pattern (i.e. polarity and amplitude) was known in all phases, then energizing the phase having the lowest residual flux is the best method. Depending on the residual flux polarity in two other legs, dynamic and waiting fluxes of the core are equal in a specific moment after closing 
the first phase. This moment is related to one excellent opportunity for energizing two other phases without core saturation. This method is known as fast closing method.

The other closing methods are also available, such as delayed closing method in which the second and third circuit breakers operated after a 20-40 ms delay, and instantaneous closing method in which all phases closed at the same time [1]. The second method is applicable for cases in which the residual flux equals zero in one phase and in the other phases it has high amplitude and reverse polarity, after limiting.

\section{Studying the resulted ferroresonance by controlled switching}

As it was mentioned earlier, many studies have been conducted for reducing inrush current. However, using controlled switching is the best method. Controlled switching was studied completely in [1]. Considering that the capacitance effect is high in ground networks, and the conceptions presented in section (3.4) about switching conditions and its effect on ferroresonance phenomenon occurrence, it seems that during the usage of controlled switching method in ground power networks, this phenomenon is most likely practically.

For studying the stated items, the power network existing in Fig. 6 that is practically one EMTP models and here have changed partially for synchronous studying of ferroresonance and inrush current phenomena, will be evaluated [11]. In this network, a power transformer have energized in no load condition, by two ground cables that each of them have the length of $1200 \mathrm{~m}$ and a circuit breaker whose poles on/off time is controllable. The used power network has a voltage level of $132 \mathrm{kv}$, and the considered transformer has $\mathrm{D} / \mathrm{Y}$ connection and a voltage level of $132 / 20 \mathrm{kv}$. Also the transformer have assumed in saturated condition.

For studying and presenting the resulted ferroresonance phenomenon during the usage of controlled switching, first the network status is evaluated in conditions without any control method, and then with controlled switching method. Time parameters existing in the simulation were selected using [12]. In other words, using above concepts about controlled switching, at first the first pole is switched in time of $0.02 \mathrm{~s}$ and the third pole is switched in time of $0.0233 \mathrm{~s}$ and finally the second pole is switched in time of $0.0266 \mathrm{~s}$.

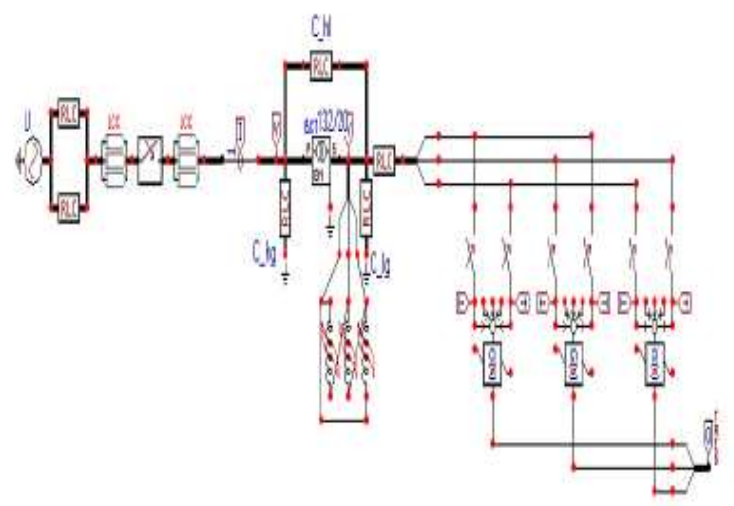

Fig.7 presents the network's wave form in a status that no control method is used for reducing inrush current. As it can be seen in this figure, the network has a high current that is damped gradually after few cycles. The network wave form in a status that controlled switching method was used to reducing inrush current is presented in Fig.8. As it can bee seen from this figure, although this method reduce the inrush current but the network current was increased.

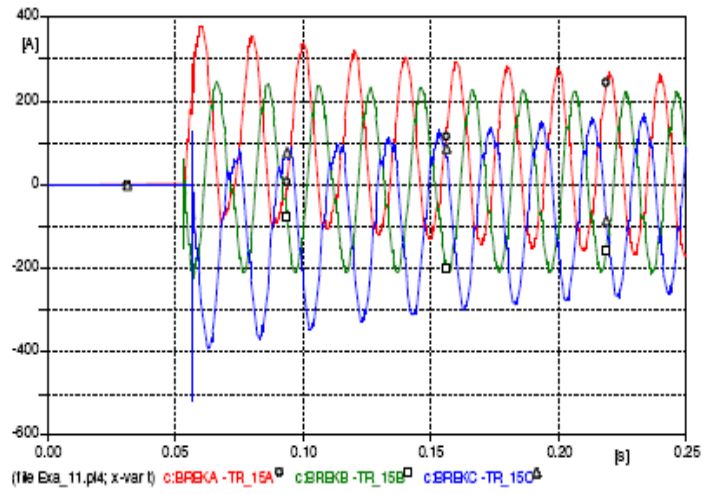

Fig.7. current's wave form of the network without controlled switching

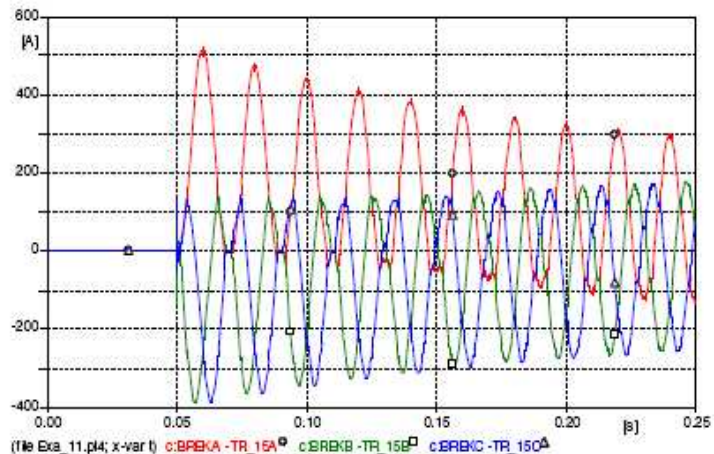

Fig.8. current's wave form of the network using controlled switching

According to issues explained in section (3), it is expected to observe transient voltage drop in presence of inrush current in power networks. However, in ground power networks this case wasn't observed due to the effect of network capacitance, and a voltage damping and transient increase is seen. Fig.9 shows this case in the network in the status that no control method was used. Using controlled switching method, the condition mentioned in section (3.4) for creating ferroresonance phenomenon will be available, and we will face to a condition that two transient phenomenon appeared synchronously. In other word, the main reason of voltage increasing in Fig.8 is also related to this phenomenon. Voltage wave form during the usage of controlled switching is shown in Fig.10. The amplitude of additional transient voltage increased significantly in these conditions, and in fact the ferroresonance phenomenon is produced. 


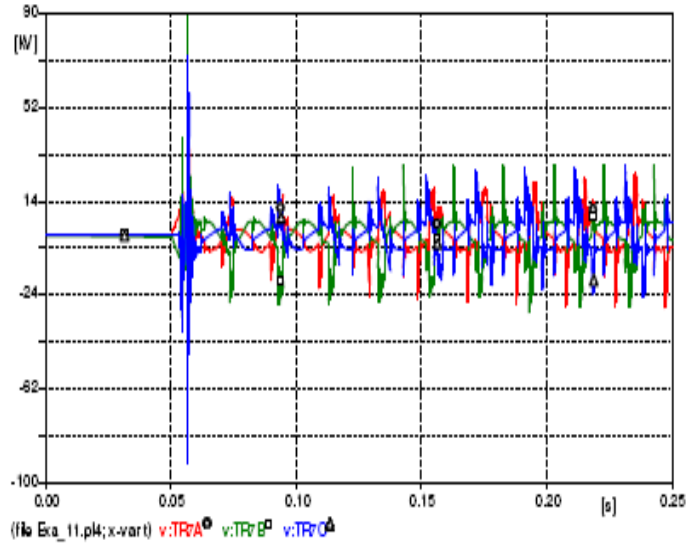

Fig.9. voltage wave form of the network without controlled switching

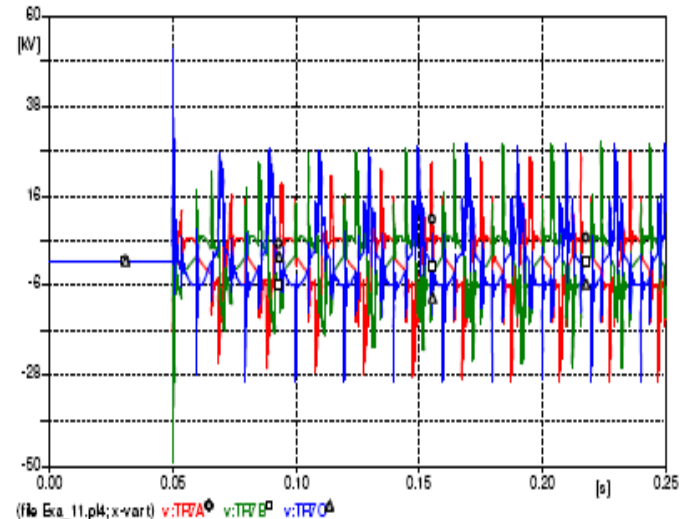

Fig.10. voltage wave form of the network using controlled switching

Even though the existence of inrush current in power networks, a different harmonic spectrum have produced in network current. Fig.11 shows the harmonic spectrum of one of the phase's current in a condition that only up to 10th order harmonic is considered. As it can bee seen, the order of harmonic 2 th is higher than others that actually it is used for detecting inrush current from error conditions of power network. Producing ferroresonance results in increasing the harmonics existing in inrush current that consequently reduce the power quality of the network. This is shown in Fig.12.

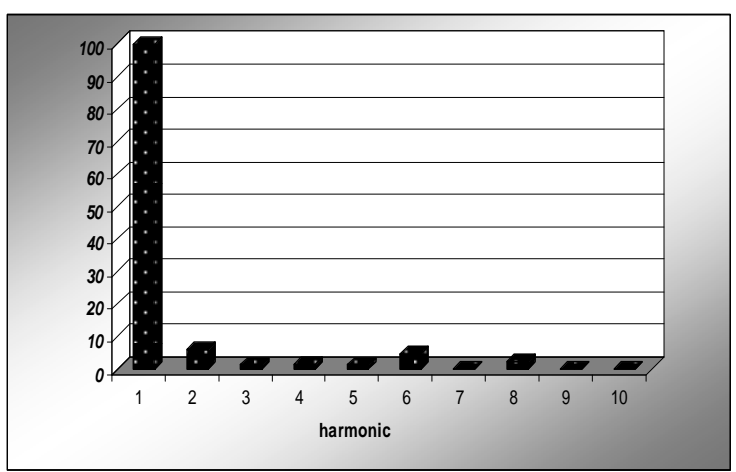

Fig.11. current harmonic spectrum in one of the phases in without controlled switching conditions

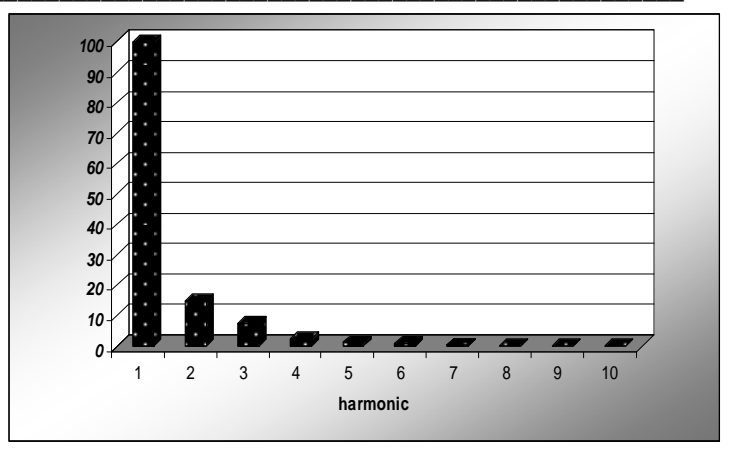

Fig.12. current harmonic spectrum in one of the phases in controlled switching conditions

\section{CONCLUSION}

Energizing the power transformers usually results in an inrush current that has very high amplitude. Controlled switching method is usually used for reducing this current. Ferroresonance phenomenon is also usually produced by the line's capacitance reactance and nonlinear inductive reactance. Results of the conducted simulation and theoretical observations show that, although controlled switching method have an adequate results in aerial networks, but in ground networks not only did not reduce the inrush current, but also increased the voltage and current levels due to the resulted ferroresonance. This is the first time that these two transient phenomenons and their major reasons have studied in one research. Future studies in this area will be focused on reducing inrush current in ground power systems and situations in which controlled switching is used.

\section{ACKNOWLEDGEMENTS}

The writers of this paper offer their best thanks and appreciations to those whose research efforts were used in this paper.

\section{REFERENCES}

[1] J. H. Brunke and K. J. Fröhlich, "Elimination of transformer inrush currents by controlled switching, Part I_II," IEEE Trans. on Power Delivery, vol. 16, No. 2, April 2001.

[2] Electrical Transmission and Distribution Reference Book. Pittsburgh, PA: Westinghouse Electric Corporation.

[3] ANSI/IEEE C37.102-1987, IEEE Guide for AC Generator Protection. ANSI/IEEE, 1987

[4] M. Steurer, K. Fröhlich, "The impact of inrush currents on the mechanical stress of high voltage power transformer coils," IEEE PWRD vol. 17, No. 1, pp.155-160, 2002.

[5] R.L. Sharp and W.E. Glassburn, "A transformer differential relay with second harmonic restraint," AIEE Trans., 77:913-918, December 1958.

[6] R.R. Larson, A.J. Flechsig and E.O. Schweitzer "An efficient inrush detection algorithm for digital computer relay protection of transformer," IEEE Trans., 97:323, March-April 1978.

[7] T.S. Sidhu and M.S. Sachdev, "On line identification of magnetizing inrush and internal faults in three-phase transformers," IEEE Trans., PWRD-7(4):108-117, October 1992.

[8] Slow Transient Task Force of the IEEE Working Group on Modeling and Analysis of System Transients Using Digital Programs, "Modeling and analysis guidlines for slow transients - Part III: The study of 
ferroresonance," IEEE Trans. on Power Delivery, vol. 15, No. 1., Jan.

2000 , pp. $255-265$.

[9] S. Santoso, R. C. Dugan, T. E. Grebe, and P. Nedwick, 2001, "Modeling ferroresonance phenomena in an underground distribution system", International Conference on Power Systems Transients (IPST), Rio de Janeiro, Brazil, June 24-28.

[10] Morav, et al., Point-on-wave controlled switching of high voltage circuit breakers, CIGR' E, Session 2002, paper 13-201.

[11] "Electro-magnetic transients program, rule book," in Bonneville Power Administration, Revised. Portland, OR: EMTP, 1980.

[12] L. Prikler, G. B'anfai, G. B'an a, P. Becker, "Reducing the magnetizing inrush current by means of controlled energization and de-energization of large power transformers", Electric Power Systems Research 76 (2006) 642-649.

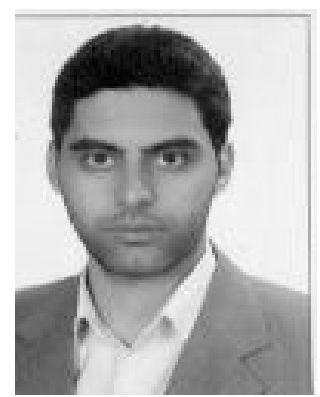

Amin Akrami was born in Shiraz, Iran in 1987. He obtained the B. Sc degree in 2008 from Feiz University Kashan, Iran. He is student M. Sc in Azad Islamic University, Dezfool branch now. His current research interests include Application for advance Solid-State Lamps, Modeling Ferroresonance phenomenon an underground distribution system, Reduction Inrush Current.

$\mathrm{He}$ is a Member of the Institute Electrical Engineers of Iran.

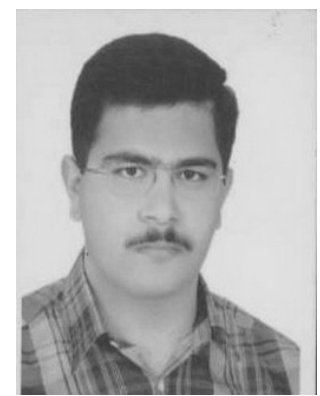

Mohammad Ali Ghaderi was born in Shiraz, Iran in 1985. He obtained the B. Sc degree in 2008 from Kazeroon Islamic Azad University, Iran. He is student M. Sc in Azad Islamic University, Dezfool branch now.

His current research interests include Optimal Power flow, Modeling Ferroresonance phenomenon an underground distribution system, Reduction Inrush Current.

$\mathrm{He}$ is a Member of the Institute Electrical Engineers of Iran.

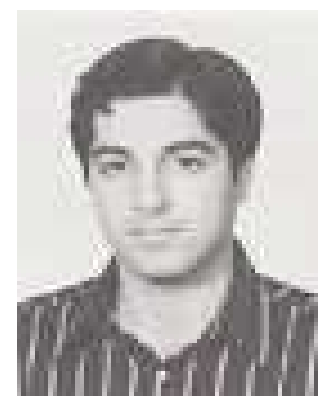

Saeed Rostami Ghadi was born in Qaemshahr, Iran in 1986. He obtained the B. Sc degree in 2008 From Aliabad Azad Islamic University, Iran. He is student M. Sc in Azad Islamic University, Dezfool branch now.

His current research interests include Unit Commitment, Modeling Ferroresonance phenomenon an underground distribution system, Reduction Inrush Current.

$\mathrm{He}$ is a Member of the Institute Electrical Engineers of Iran. 